\title{
Assembling the Right Team-Organizational Structure in the ACA Era
}

John Bucuvalas, $M D^{1, *}$ Angela Lorts, $M D^{2}$

\author{
Address \\ ${ }^{*}, 1$ Cincinnati Children's Hospital, 3333 Burnet Avenue, Cincinnati, OH, 45229, USA \\ Email: john.bucuvalas@cchmc.org \\ ${ }^{2}$ Heart Institute, Cincinnati Children's Hospital, 3333 Burnet Avenue, Cincinnati, \\ $\mathrm{OH}, 45229$, USA
}

Published online: 11 October 2016

C Springer International Publishing AG 2016

This article is part of the Topical Collection on Pediatric Health Care Administration

Keywords Health care teams $\cdot$ Interdisciplinary $\cdot$ Outcomes $\cdot$ Chronic care · Pediatrics

\section{Opinion statement}

The health care community is seeking ways to improve outcomes by formation of teams to leverage diverse expertise, skills, and training. The concept that diversity among team members improves performance is well accepted. Nevertheless, it is challenging to put the concept into action. Bringing people together across disciplines increases the pool of available knowledge but coordination becomes difficult as teams grow in size. In the setting of complex care, teams must gather information from multiple subspecialists, synthesize the information acquired, come to decisions, and execute a plan. Complex care often involves input from and coordination with other departments, so information must flow beyond team boundaries. Reporting relationships add complexity since team members may belong to distinct departments and many individuals belong to multiple teams. Given these potential constraints, it is no surprise that putting groups together and calling them a team does not ensure that the team will be effective. Effective teams require a common purpose, organizational support, and ties, which permit trust and foster mutual accountability among team members. So leaders must acknowledge and recognize the complexity of the system in which the team operates and helps to define and foster strategies to optimize team function.

\section{Introduction}

With advances in medical science, operative procedures, and pharmaceuticals, traditional outcome metrics have improved but they do not adequately represent the results of care for patient populations. With increasing focus on the quality of health care, the goals for patients and for their providers may best be described by the tiers 
of outcomes as defined by Michael Porter [ $1 \bullet]$. Porter proposed that the tiers be defined as (1) health status achieved, (2) process of recovery, and (3) sustainability of health. Health care organizations are seeking ways to improve outcomes by leveraging diverse expertise, skills, and training. The concept that diversity among team members may improve performance is well accepted, but putting the concept into action is often met with challenges. Bringing people together across disciplines increases the pool of available knowledge and reduces departmental silos [2], but coordination is challenging for large teams [3], and diversity among team members can both enhance and inhibit collaboration [4]. In this review, we will discuss the characteristics of a good team, the trials that teams face, opportunities for improvement of team function, and then examination of the challenges and opportunities in distinct clinical scenarios.

\section{What makes a good team}

\section{Challenges for teams}

Organizational effectiveness and leadership research have helped us understand the components of a good team. Increasingly, the best productivity for effective interdisciplinary teams requires that they work in a coordinated fashion toward a common goal. Effective teams build ties among key players and adapt their structure over time to enable useful outsiders to contribute on common projects $[5,6]$. With successful teams, each player brings his or her special knowledge and capabilities, but also interpersonal relationships with the members inside and outside of the team [7]. Yet even though individual team members may have distinct and complementary expertise, effective teams require a common purpose, close ties among the members, mutual accountability, and organizational support. To reiterate, teams must have a common and shared goal and have ties that permit trust and foster mutual accountability. In addition, it is critical to recognize that these characteristics rest on an organizational structure that supports interdisciplinary efforts. It is the combination of these factors that distinguishes good teams. For more specific reading related to these concepts, please consider reference $[8 \bullet$.

The components of team failure are well described and include lack of competence, lack of trust, failure to constructively address and resolve differences, failure of commitment, lack of accountability, and inattention to results [9]. Specific strategies to address causes of team failure or dysfunction exist but they require time and may be costly [9].

\section{Teams abound in health care}

The single researcher making a critical discovery or a physician able to make diagnoses and treat patients with complex conditions based on the contents of their "black bag" and what they carry in their memory is exceedingly rare. As information grows and expertise becomes more specialized, division of labor emerges. As a result, coordination across specialties becomes critical and often occurs across traditional organizational structures. While effective coordination will foster collaboration, it comes so with a cost since it requires time to ensure 
clear communication and harmonized efforts. Distribution of decision-making authority is a challenge since physicians, who often serve as team leaders, may have less knowledge than other non-physician health care providers such as pharmacists, dietitians, social workers, respiratory therapists, and nurses. Yet, physicians may feel compelled to retain decision-making authority. While a discussion of all of the many distinct health care teams is beyond the scope of this review, we will provide some discussion of challenges as they may apply to specific examples.

Increasingly, the best productivity for complex patient-based research requires effective interdisciplinary teams with diverse competencies who work in a coordinated fashion toward a common goal. More importantly, strong professional and interpersonal ties exist among players building trust among team members, and if present, these relationships and research collaborations form an extraordinarily resilient structure. The importance of the network effectiveness cannot be underestimated. The expertise of the core players, the resiliency of the network through periods of change, and the extensive ties among the key players are markers of successful teams. Moreover, productivity and impact of research are increased with team comprised of members across disciplines and across research sites $[10 \bullet]$.

\section{Surgical teams}

Several studies have shown links between team communication and performance and patient outcomes. In 2005, the Joint Commission estimated that poor communication was the cause of nearly $70 \%$ of sentinel events [11]. In the past, surgical excellence has been focused on the technical excellence of individual surgeons. While technical excellence is critical and perhaps the most critical factor predicting outcome, it does not stand alone. Miscommunication among surgeons, anesthesiologists, and nurses increases risk for surgical complications $[11,12]$. Surgical teams have modeled safety improvement strategies used in the aviation industry to improve communication and as a result decrease the risk of errors related to human factors [12]. Errors across preoperative, intraoperative, and postoperative phases of care impact outcome. Communication breakdowns within and across phases of care are potential areas of risk and opportunities for improvement. In the postoperative phase of care, failure to identify complications and escalate care may lead to poor outcomes [12-14]. Failure to rescue from complications often results from lack of experience and also from failure of communication of front line providers with senior physicians. Patient harm may be avoided if clinical changes are recognized and the observations are communicated to decision-makers.

\section{Interdisciplinary inpatient care}

The path of the patient often traverses units and departments, and consequently, care for the individual patient may not align with the organizational 
structure. To be successful in a value-based health care system, providers need to adapt to the needs of the individual patients within the structure of a standardized approach to care. How do care teams fit into this paradigm? As a first step, let us pick an example, in this case, solid organ transplantation. This procedure and the associated care processes can serve as a model for other complex clinical care that requires interdisciplinary teams.

\section{Care in a specialty unit}

Care for the increasingly complex population of solid organ transplant recipients requires teams of subspecialists including pediatric surgeons and transplant-trained physicians as well as specialists in immunology, infectious disease, and pharmacology. In addition, front line nursing teams are now trained in transplant medicine to reliably execute care plans. The approach to improve care has invoked critical components of the chronic care model [15•] related to decision-making aids, electronic health records, and delivery system design. The best outcomes are achieved when we also leverage the knowledge of members of the interdisciplinary team. Nevertheless, we have not, as yet, comprehensively examined the potential impact of communication, varied work styles, and the types of working relationships and habits of the health care professionals on interdisciplinary teams. Specifically, how do health care professionals on interdisciplinary teams come together to share information and use their collaborative intelligence to make decisions? Due to the wide variation in fields of expertise and modes of practice, there are many opportunities for miscommunication. By understanding the factors, which may impede open and divert forms of communication, we can improve patient safety and outcomes, and decrease risk and cost.

While interdisciplinary teams have been associated with better patient outcomes $[16,17]$, the teams introduce new challenges in group coordination and management. First, they involve more players than traditional teams. Research informs us that productivity lost to coordination increases exponentially with increasing team size, and productivity actually begins to decrease beyond about 45 members [18]. Second, care teams are highly dynamic, with medical trainees (residents and fellows) and attending physicians rotating through the team at different intervals. With new members constantly joining and leaving the team, the team cannot fully capture known benefits of team stability for short-term performance [19]. Third, well-documented social and cultural dynamics often inhibit communication among players who may be divided by social status, placement in the vertical hierarchy, and/or professional background [20]. Complex care involves constant input from and coordination with other departments (e.g., consulting physicians), so information must flow beyond even ill-defined team boundaries for effective coordination. Reporting relationships add complexity since almost all members belong to department distinct from the team, and many belong to multiple teams. In the end, we have a dynamic team conducting complex work functioning in a matrix organizational structure. It is no surprise that putting these groups together and calling them a team does not ensure that they will work together effectively.

The setting in which the team functions may impact outcome. Ethan Bernstein has observed the critical role of privacy for team function [21•]. Based on a 


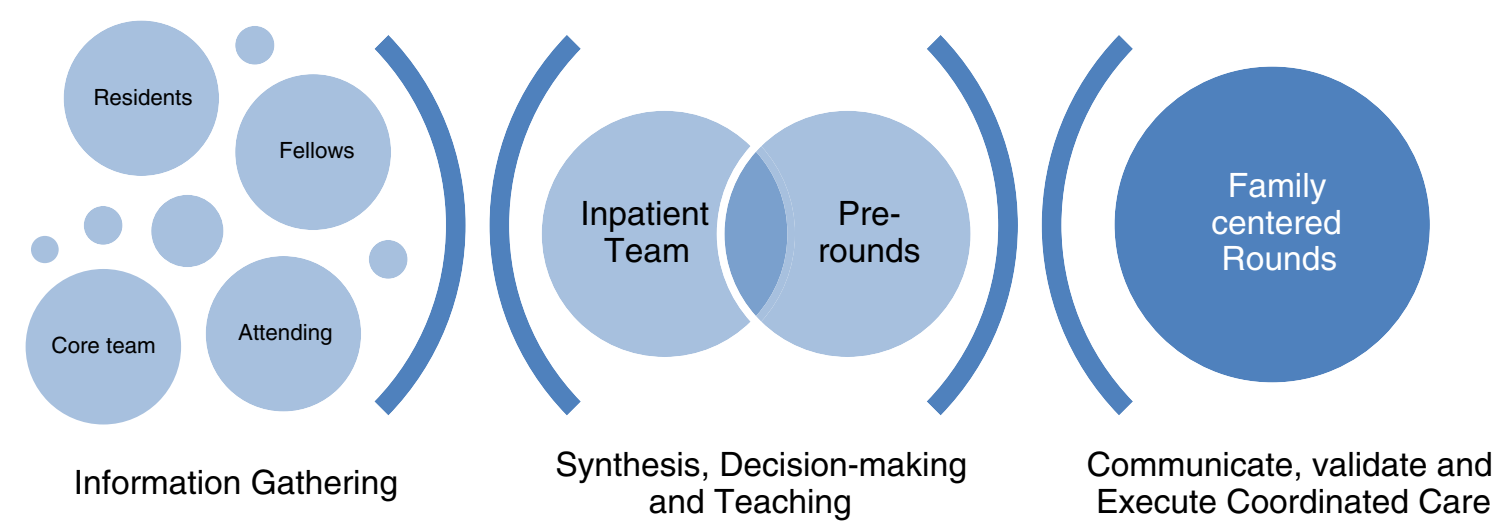

Fig. 1. Four-step process of care.

qualitative study and then field experiment of a large manufacturing company in Southern China, Bernstein and colleagues found that an opportunity to permit groups working together to have privacy was associated with increased innovation and higher productivity. So while the buzz word has become transparency, openness in the absence of privacy may make the team member uncomfortable to state an opinion for fear of failure. Remarkably, transparency may compromise application of the diverse knowledge among team members and as a result reduce productivity. So bringing the team together without attention to a balance between privacy and transparency may compromise effectiveness. How might this be relevant to health care? The process of care may be considered to include four steps: gathering of information, synthesis of information across disciplines, decision, and execution of the plan (Fig. 1). Patients and family members are included in rounding discussions, which means some of the conversations that doctors and other care providers used to have among themselves have become public. While the Socratic method may have previously been the norm for teaching residents, getting something wrong in front of the patient and family may lead to loss of credibility, perhaps not worth the benefit of learning. Moreover, if the patient and family witness real-time problem-solving in a complex situation, anxiety and confusion may occur. Problem-solving and teaching in a private space, to synthesize information and do complex decision-making, may permit more open discussion among the teams. Then, the providers could validate the plan in public with the family and staff.

A Real Conversation- Consider the Solution Spaces

A young woman with clinical changes after liver transplantation

Hepatologist: She has increased heart rate one month after liver transplantation. She developed adenovirus, elevated liver tests and has an anastomotic biliary stricture. Her mental status is deteriorating I think she should move to the ICU

Cardiologist: I have seen this before. She has a second degree AV block, elevated BNP and a dyskinetic left ventricle. I would be really concerned about progression in the face of an inflammatory myocardial process. I think she should go to the $\mathrm{CICU}$

Fig. 2. Example on considering the solution spaces. 


\section{Summary}

Finally, Shore et al. [22•] examined how members of a network collect information and solve problems. Problem-solving involves both searching and gathering information and exploration for solutions. Interestingly, the results showed that highly clustered teams were more effective at gathering and generating information but were less innovative in the solution space, perhaps more likely to come to the same conclusions than less clustered groups. The authors noted that it was important to recognize the dichotomy. Why is this important for health care teams? Teams that are highly clustered may fall privy to cognitive bias, and fail to consider solutions outside of their immediate sphere of work and potentially delay diagnosis and treatment (Fig. 2).

Given this level of complexity, what strategies might make sense to building a team and optimizing its performance? At a first level, it is critical to recognize that the team and its function impacts outcome, value, patient experience, and professional satisfaction for team members. It is also essential to acknowledge and recognize the complexity of the system and the potential pitfalls in which the team operates. In our discussion here, we have given three examples: a research team, surgical team, and an interdisciplinary inpatient team. But there are myriad others. Some steps to consider that may help to optimize performance have been outlined by Katzenbach and Smith [23]. Careful selection of members for skill and skill potential in the context of a clear goal is critical. There must be some clear rules for behavior and privacy. Early successes that can be celebrated are important, and the leaders should be aware of opportunities for professional development and recognition of the team members. The team must be open to new ideas and learning. While these issues may seem obvious, they are often overlooked in the busy health care environment.

\section{Acknowledgments}

The authors thank Ethan Bernstein PhD, JD, MBA, Assistant Professor of Leadership and Organizational Behavior at the Harvard Business School for his review and thoughtful comments.

\section{Compliance with Ethical Standards}

Conflict of Interest

The authors declare that they have no conflict of interest.

Human and Animal Rights and Informed Consent

This article does not contain any studies with human or animal subjects performed by any of the authors. 


\section{References and Recommended Reading}

Papers of particular interest, published recently, have been highlighted as:

- Of importance

1. $\quad$ Porter ME. What is value in health care? N Engl J Med. 2010;363:2477-81.

While more than 5 years old, this short editorial gives a framework for health care in the twenty-first century and serves to set the foundation for the role of interdisciplinary care provider teams.

2. Galbraith JR. Organization design: an information processing view. Interfaces. 1974;4:28-36.

3. Hollenbeck JR, Beersma B, Schouten ME. Beyond team types and taxonomies: a dimensional scaling conceptualization for team description. Acad Manag Rev. 2012;37:82-106.

4. Knippenberg DV, Schippers MC. Work group diversity. Annu Rev Psychol. 2007;58:515-41.

5. Ancona D, Bresman H, Caldwell D. The X factor: six steps to leading high-performing X-teams. Organ Dyn. 2009;38:217-24.

6. Ancona D, Bresman H. X-Teams: how to build teams that lead, innovate, and succeed. Boston: Harvard Business School Press; 2007.

7. Wenger EC, Snyder WM. Communities of practice: the organizational frontier. Harv Bus Rev. 2000;78:139-45.

8. Harvard Business Review 10 must reads on teams. Harvard Business School Publishing Corporation. Boston, MA. 2013.

This book includes ten articles from HBR on team and can serve as a guide and reference independent of the industry.

9 . Lencioni P. The five dysfunctions of a team: a leadership fable. San Francisco: Jossey-Bass; 2002.

10. Page SE. The difference: how the power of diversity creates better groups, firms, schools and societies. Princeton: Princeton University Press; 2007.

Scott Page is a computer scientist with a social science bend who makes a compelling case for diversity among team members independent of the field of work or study.

11. The Joint Commission. Sentinel events statistics-June 30, 2006. Available at: http://www. jointcommission.org/SentinelEvent/Statistics/. Accessed 15 Sept 2006.

12. Awad SS, Fagan SP, Bellows C, Albo D, Green-Rashad $\mathrm{B}$, De la Garza M, et al. Bridging the communication gap in the operating room with medical team training. Am J Surg. 2005;190:770-4.

13. Johnston MJ, Arora M, King D, Bouras G, Almoudaris A, Davis R, et al. A systematic review to identify the factors that affect failure to rescue and escalation of care in surgery. Surgery. 2015;157:752-63.
14. Rogers SO, Gawande AA, Kwaan M, Puopolo AL, Yoon CL, Brennan TA, et al. Analysis of surgical errors in closed malpractice claims at 4 liability insurers. Surgery. 2006;140:25-33.

15. Coleman K, Austin BT, Brach C, Wagner EH. Evidence on the chronic care model in the new millennium. Health Aff. 2009;28:75-85.

This article builds upon the chronic care model by Wagner first proposed in 2000. This article complements the position piece proposed by Porter (reference \# 1).

16. Shortell SM, Marsteller JA, Lin M, Pearson ML, Wu SY, Mendel $\mathrm{P}$, et al. The role of perceived team effectiveness in improving chronic illness care. Med Care. 2004;42:1040.

17. Lemieux-Charles L, McGuire WL. What do we know about health care team effectiveness? A review of the literature. Med Care Res Rev. 2006;63:263-300.

18. Coutu D. Why teams don't work: an interview. In: Richard Hackman J, editor. Harvard Business Review 10 must reads on team. Boston: Harvard Business School Publishing Corporation; 2013.

19. Katz R, Allen T. Investigating the Not Invented Here (NIH) syndrome: a look at the performance, tenure, and communication patterns of $50 \mathrm{R} \& \mathrm{D}$ Project Groups. R\&D Manag. 1982;12:7-20.

20. Nembhard IM, Edmondson AC. Making it safe: the effects of leader inclusiveness and professional status on psychological safety and improvement efforts in health care teams. J Organ Behav. 2006;27:941-66.

21. Bernstein E. The transparency paradox: a role for privacy in organizational learning and operational control. Adm Sci Q. 2012;57:181.

While this paper focuses on observations in a factory setting, the applicability to health care particularly inpatient care is very evident. It shows us that the health care industry can learn from other exemplars.

22. Shore J, Bernstein E, Lazer D. Facts and figuring: an experimental investigation of network structure and performance in information and solution spaces. Harvard Business School Organizational Behavior Unit Working Paper No. 14-075.

Available at SSRN: http://ssrn.com/abstract=2412492. doi: 10 . $2139 / \operatorname{ssrn} .2412492$.

23. Katzenbach JR, Smith DK. The discipline of teams. In: Harvard Business Review 10 must reads on teams. Boston, Harvard Business School Publishing Corporation; 2013. 